\title{
Multiple sclerosis: depression and disability are globally shared issues of concern
}

\author{
Victor M. Rivera \\ Department of Neurology, Baylor College of Medicine, Houston, TX 77025, USA.
}

Correspondence to: Dr. Victor M. Rivera, Department of Neurology, Baylor College of Medicine, Cambridge Street 7200, 9th Floor, Houston, TX 77025, USA. E-mail: vrivera@bcm.edu

How to cite this article: Rivera VM. Multiple sclerosis: depression and disability are globally shared issues of concern. Neuroimmuno/ Neuroinflammation 2018;5:12. http://dx.doi.org/10.20517/2347-8659.2018.16

Received: 30 Mar 2018 Accepted: 31 Mar 2018 Published: 18 Apr 2018

Science Editor: Athanassios P. Kyritsis Copy Editor: Guang-Zhe Zhu Production Editor: Huan-Liang Wu

While multiple sclerosis (MS) is more common among Caucasian populations, its prevalence is increasingly noted in ethnic groups that had previously been considered to have a low frequency of the disease. Epidemiologic studies indicate a considerable augmentation of MS presence in areas such the Middle East $^{[1]}$ and Latin American countries ${ }^{[2]}$. Along with the general clinical effects of this complex neurological disorder is the impact exerted by some of its comorbid neuropsychiatric manifestations particularly depression, described as affecting three times higher MS patients than the general population ${ }^{[3]}$. Literature and general perceptions had suggested clinical depression, although chronic in most MS cases, was unrelated to disability progression or disease course ${ }^{[4,5]}$.

A Saudi Arabia study ${ }^{[6]}$ published in Neuroimmunology and Neuroinflammation, acquired data from all geographic regions of the Kingdom involving 598 MS patients, and finding that $97.7 \%$ had some degrees of depression as assessed with the patient health questionnaire, a reliable and valid measure of depression severity. In this study, most had mild-to-moderate depression. The Saudi Arabian investigators correlated these data with scores obtained from disability quantified with the patient determined disease steps which has a strong correlation with the scores derived from the expanded disability status scale, the cardinal marker of neurological disability in MS. There was a significant association between patients' level of neurological disability and severity of depression $(P<0.001)$. Interestingly, none of the patients reported absence of depression had a moderate or severe disability while those with moderately severe or severe depression had the highest percentages of severe disability. Aspects that escaped the authors explanation was the fact that severe depression was more prominent in patients residing in the northern areas of the country and that $13 \%$ of the subjects were foreigners, their country origin was not reported. Saudi Arabia has a medium to high MS prevalence $(\geq 40 / 100,000)^{[7]}$ has substantial immigrant population from nearby

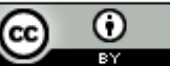

(C) The Author(s) 2018. Open Access This article is licensed under a Creative Commons Attribution 4.0 International License (https://creativecommons.org/licenses/by/4.0/), which permits unrestricted use, sharing, adaptation, distribution and reproduction in any medium or format, for any purpose, even commercially, as long as you give appropriate credit to the original author(s) and the source, provide a link to the Creative Commons license, and indicate if changes were made.

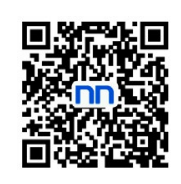


countries (and most recently refugees from Syria and Yemen), Asian expatriates and many westerners employed in professional and technical jobs. The reported phenomenon of people moving from a highrisk to a low-risk area carry the MS risk with them if the migration took place after age 15 continues to be discussed $^{[8]}$ but these epidemiologic aspects deserve further study in Saudi Arabia. Recent attention has been placed on the sociological and/or biological behavior of immigrants with MS moving from a lower to a higher risk country ${ }^{[9]}$. In this series, as it is universally observed, women's prevalence was higher (64.2\%) with a female: male ratio of about 2:1. Other findings of note extracted from the data of the Saudi Arabian study are the higher prevalence of depression in young individuals ages $26-35$ years $(P=0.001)$ and with a higher education $(P=0.001)$, but predominant as well in people with the lowest income $(<3000$ monthly $\mathrm{SR}$, equivalent to $800 \mathrm{USD})$.

The Saudi Arabian study provides the first-time evidence of a direct and significant relationship between depression and neurological disability in MS patients. In this sample, all the patients were being treated with a disease modifying therapy. The association of depression with the medication class remains unclear although the only two cases receiving Alemtuzumab (Lemtrada ${ }^{\circ}$ ) scored with severe depression and the highest percentages of moderately severe and severe depression were noted with $\beta$ interferons 1-a (Avonex; Rebif $^{\bullet}$ ) and 1-b (Betaferon ${ }^{\circledR}$ ), as well as the oral product Dimethyl-fumarate (Tecfidera ${ }^{\circledR}$ ). The presence of depression with its tremendous variety of emotional states in the majority of people with MS, is a factor requiring early identification and appropriate management in view of the impact to a person's quality of life and it is associated with progression of disease as well as neurological disability.

\section{DECLARATIONS}

\section{Authors' contributions}

The author contributed solely to the paper.

\section{Financial support and sponsorship}

None.

\section{Conflicts of interest}

There are no conflicts of interest.

\section{Patient consent}

Not applicable.

\section{Ethics approval}

Not applicable.

\section{Copyright}

(c) The Author(s) 2018.

\section{REFERENCES}

1. Browne P, Chandaratna D, Angood C. Atlas of multiple sclerosis 2014. Neurology 2014;83:1022-4.

2. Melcon MO, Melcon CM, Bartoloni L, Cristiano E, Duran JC, Grzesiuk AK, Cabrera Gomez JA. Towards establishing MS prevalence in Latin America and the Caribbean. Mult Scler 2013;19:145-52.

3. Minden SL, Schiffer RB. Affective disorders in multiple sclerosis: review and recommendations for clinical research. Arch Neurol 1990;47:98-104.

4. Depression. Available from: www.nationalmssociety.org/depression [Last accessed on 29 Mar 2018].

5. Koch MW, Patten S, Berzins S, Zhornitsky S, Greenfield J, Wall W, Metz LM. Depression in multiple sclerosis: a long term longitudinal study. Mult Scler J 2015;21:76-82.

6. Alhazzani AA, Alqahtani MS, Ogran H, Abuhawi OH, Asiri AY, Al-Hanash AM, AlQahtany RA, Alfaifi AA, Asiri AA, Asiri MA. Depression severity and its predictors among multiple sclerosis patients in Saudi Arabia: a cross-sectional study. Neuroimmunol Neuroinflammation 2018;5:8. 
7. Bohlega S, Inshasi J, Tahan ARA, Madani AB, Qahtani H, Rieckmann P. Multiple sclerosis in the Arabian gulf countries: a consensus statement. J Neurol 2013;260:2963.

8. Alter M, Leiboweitz U, Speer J. Risk of multiple sclerosis related to age at immigration to Israel. Arch Neurol 1966;15:234-7.

9. Rivera VM. Multiple sclerosis as a universal disease and the challenges to immigrants in high prevalence countries. Eur $J$ Neurol 2018;1:701. 